laryngis is due to acid reflux. He postulates that in patients with reflux oesophagitis the acid contents of the oesophagus may be regurgitated still higher up, particularly at night, thus causing an inflammatory reaction in the posterior part of the larynx. Nine patients pachydermia were investigated with this possibility in mind, five having symptoms suggestive of oesophagitis and three a sensation of a lump in the throat in addition to hoarseness, which was common to all of them. Acid barium swallows ${ }^{2}$ were performed, and in all nine patients the findings were consistent with a diagnosis of reflux oesophagitis, two patients showing in addition reflux into the pharynx. The patients were treated with suitable antacid therapy, and all improved symptomatically and objectively after an average of six to eight weeks.

Several questions arise from this investigation. For instance, why is pachydermia, which is an extremely uncommon condition, not seen more often in cases of hiatus hernia? Furthermore, if acid reflux through the cricopharyngeus is the cause of the laryngeal lesion, is it not likely that similar inflammatory changes would occur in the postcricoid region of the hypopharynx? One would also have expected nocturnal coughing to be a symptom, since the interarytenoid area of the larynx is sensitive to irritation of any kind. The presence of oesophagopharyngeal ,reflux in two of the patients as shown by acid barium swallows may be questioned on the grounds that the stimulus responsible for the adnormal oesophageal movements which occurred may have been exceptionally potent. A more accurate and sensitive measurement of acidity in the oesophagus is provided by the use of $\mathrm{pH}$ electrodes which can be left in the lumen of the oesophagus overnight. $^{3} 4$ Nevertheless, the view that pachydermia is due to acid reflux deserves further attention.

1 Delahunty, J. E., Fournal of Laryngology, 1972, 86, 335.

2 Donner, M. W., Silbiger, M. L., Hookman, P., and Hendrix, T. R., Radiology, 1966, 87, 220.

4 Spencer, J., British fournal of Surgery, 1969, 56, 912.

\section{Royal College of Surgeons}

Sir Edward Muir, consulting surgeon to King's College Hospital, was elected President of the Royal College of Surgeons last week. In recent years the college has notably extended its influence throughout the country and Sir Edward enters office at a time when further growth of its activities is likely.

Many years ago the Royal College of Surgeons of England broke away from its traditional role as an examining body, and during the presidency of Lord Moynihan in 1928 the first research departments were established. After the second world war these departments increased in number and took on the responsibilities of postgraduate teaching as well as research. Twenty-one years ago the Institute of Basic Medical Sciences was formed in collaboration with the University of London, and the departments of anatomy, physiology, pathology, pharmacology, and later biochemistry were incorporated in the institute. The College also set up departments of anaesthetics and of dental science and a research department of ophthalmology. More recently a research department of surgical sciences has been established under the directorship of Lord Brock.

At the instigation of the late Sir Frank Holdsworth, of
Sheffield, the College took the lead among the four Royal Colleges of Surgeons of the British Isles in organizing the scheme for higher surgical training, a scheme which has put some sort of order into the period of post-fellowship training. In planning and implementing this scheme the colleges have had the full co-operation of the relevant specialist associations and of the university professors of surgery.

There has always been a tendency to regard the College as a London College rather than the surgical college of England and Wales. London surgeons have nearly always formed a majority on the council. During the last decade there has been a move to spread the College activities beyond the confines of central London. An increasing proportion of the members of the court of examiners have come from the provinces. When Sir Harry Platt was president the first attempt was made to take the College outside London by holding the annual meeting of Fellows and members in the provinces, and this is now done every alternate year. The first of these meetings was in Manchester in 1955.

During the last few years a much closer association with both undergraduate teaching schools and with district hospitals outside London has been established. Following a pilot scheme which received the support of the Numield Provincial Hospitals Trust, regional advisers and surgical tutors working in the main district hospitals throughout the country have been appointed. Regular meetings of the advisers and tutors are held at the College, and thus the representatives of the College are enabled to organize surgical training in their own areas in collaboration with the postgraduate deans of medical schools. These moves have been fostered and advanced under the presidency of Sir Thomas Holmes Sellors. Thus Hunterian lectures have been delivered in Southampton and in Darlington and a Moynihan lecture appropriately in Leeds. The president during his term of office has paid many visits to provincial centres to discuss with both senior and junior staff the means of providing the right sort of postgraduate education which can be given to those holding posts in the National Health Service. In recognizing posts in hospitals for surgical training emphasis has been laid on the need for junior doctors to have time for study, on the provision of adequate library facilities, and on the responsibility of consultants to train their juniors. The move in some provincial centres to provide in-service courses in the basic sciences for those taking the primary examinations in surgery or anaesthesia has had the full support of the council of the College. During the last three years the director of surgical studies of the College has visited more than 50 district hospitals or regional centres throughout England and Wales and discussed their problems with consultant and junior staff. In the main he found that the majority of surgeons in training posts were satisfied with the experience which they were receiving, but there were still far too many who were overburdened by service commitments, and either had not the time or expressed themselves as too tired to make use of the facilities which were being offered.

The President's term of office will go down as one in which the College has tried to spread the facilities for adequate postgraduate training in surgical subjects throughout the provinces and to carry the College's activities far beyond the building on the south side of Lincoln's Inn Fields. It will also be remembered as a period in which, guided by the President's breadth of vision, the College has strengthened and developed its links with other colleges, both surgical and medical, in Britain and overseas. 